\title{
The Catalytic Synthesis of Higher Ketones from 2-Propanol*
}

\author{
by Michio Araki** and Yoshihide Kotera**
}

\begin{abstract}
Summary: The catalytic activities of $\mathrm{Cu}_{-} \mathrm{Cr}_{2} \mathrm{O}_{3}-\mathrm{ZnO}$ and $\mathrm{Cu}-\mathrm{ZnO}$ systems for vapor phase condensation of 2-propanol were studied. The reaction was carried out by a flow method under the conditions of atmospheric pressure and $L H S V=2 \mathrm{hr}^{-1}$. The surface area and grain size of metallic copper on the used catalysts were measured by carbon monoxide adsorption and $X$-ray diffraction methods, respectively.

As the reaction products, higher ketones such as 4-methyl-2-pentanone (MIBK), 2,6dimethyl-4-heptanone (DIBK) and 2,6,8-trimethyl-4-nonanone (TMN) were obtained in high yield at about $250^{\circ} \mathrm{C}$ in addition to acetone which was thought to be an intermediate compound to above ketones.

The catalytic activity for condensation was considered to be caused by the existence of metallic copper on the catalysts and therefore, a higher total yield of condensation products was obtained by using a catalyst with larger surface area of copper on it.

Catalysts which contain larger amount of copper, have larger grain size of metallic copper, but no exact correlation between grain size of copper and the catalyst activity was found.

When 2-propanol was passed over the three-component catalyst with atomic ratio of $\mathrm{Cu}$ : $C r: Z n=0.5: 1: 1$ at $255^{\circ} \mathrm{C}$, the highest activity for condensation was obtained, namely, yields of MIBK, DIBK and TMN were 29\%, 27\% and 13\% (based on 2-propanol fed), respectively.
\end{abstract}

\section{Introduction}

It has been well known that catalysts composed of copper, chromium oxide and zinc oxide are industrially used for methanol synthesis or carbon monoxide-shift conversion; because they have higher activity and selectivity at lower reaction temperature.

During the study of dehydrogenation of 2propanol, it was found that on these catalysts 2-propanol was converted to higher ketones such as 4-methyl-2-pentanone (MIBK), 2,6-dimethyl4-heptanone (DIBK) and 2,6,8-trimethyl-4-nonanone (TMN) in high yield in one step.

Copper is known to be very important for the condensation reaction and several papers have discussed this problem ${ }^{1) \sim 5)}$.

Ipatieff et al. stated that only copper-alumina and copper-zinc oxide-alumina catalysts with both dehydrogenating and dehydrating activities were effective for condensation of sec-alcohols and/or ketones $^{11}$. Kudo suggested that only in the presence of zinc oxide or magnesium oxide, copper was active for the condensation of 2-propanol ${ }^{2}$.

Authors performed the condensation reactions

* Received J 6, 1973.

** National Chemical Laboratory for Industry (2-19-19, Mita, Meguro-ku, Tokyo 153) on copper-chromium oxide-zinc oxide and copper-zinc oxide catalysts, and the details of the state of copper on the catalysts were examined by X-ray diffraction and carbon monoxide adsorption methods. In this paper, the results of the above tests are described and the relationships between the catalytic activities and the surface area of copper are discussed.

\section{Experimental}

\subsection{Catalysts}

Three-component catalysts composed of copper, chromium oxide and zinc oxide were prepared by the following way ${ }^{6}$. Commercial cupric oxide powder was dissolved in a chromic acid solution, into which zinc oxide powder was added and kneaded for several hours in a motor-driven mortar. The resulting paste was dried at room temperature and the dried mass was crushed. Granules of 30 40 mesh were carefully reduced with a mixture of hydrogen and carbon monoxide $(2: 1)$ at $250^{\circ} \mathrm{C}$ for $5 \mathrm{hr}$ before the run.

In the preparation of a series of two-component catalysts ${ }^{7)}$ composed of copper and zinc oxide, commercial zinc oxide powder was kneaded for several hours with wet basic copper nitrate, which had been precipitated by mixing copper nitrate

Volume 15, No. 1, May 1973 
solution and aqueous ammonia, and dried. The dried mass was crushed and heated in a stream of nitrogen at $250^{\circ} \mathrm{C}$ until the evolution of nitrogen oxide was not detected in the effluent gas. Then the granules were carefully reduced in the reactor with flowing hydrogen at $250^{\circ} \mathrm{C}$ for $5 \mathrm{hr}$ before the run.

In the preparation of one-component catalysts such as zinc oxide and copper, after shaping and crushing, these oxides were reduced by the same way as two-component catalysts.

In the preparation of copper-alumina catalyst, wet basic copper nitrate and precipitate from sodium aluminate solution with carbon dioxide were kneaded and dried. After crushing, the granules were treated by the same way as twocomponent catalysts.

The catalysts used in this work were listed in Table 1.

\subsection{Apparatus and Procedures}

The reaction was carried out by using a conventional flow type reactor with a fixed bed $(1 \mathrm{ml}$ ), under the conditions of atmospheric pressure, $\mathrm{LHSV}=2 \mathrm{hr}^{-1}$ and the temperature of $180 \sim 260^{\circ} \mathrm{C}$. The apparatus had a mortor-driven syringe for feeding 2-propanol, a preheater, a stainless steel reactor heated by a fluidized sand bath, a collector for liquid products and a gas flow meter.

\subsection{Analyses}

The analyses of the reaction products were carried out with gas chromatography, mass spectrometry and infrared spectroscopy.

\subsection{X-Ray Diffraction}

The X-ray diffraction diagram of the catalysts was obtained with Ni-filtered $\mathrm{Cu}-\mathrm{K} \alpha$ radiation using D-3F type diffractometer (Rigaku Denki Co.). - Size of copper grain was calculated by means of following Scherrer's equation ${ }^{8}$ ).

$$
D_{\mathrm{hk} 1}=K \lambda / \beta \cos \theta
$$

In this study, $D_{200}$ was adopted as a measure of copper grain, because the peak due to 200 plane of metallic copper was strong and isolated from others.

\subsection{Carbon Monoxide Adsorption Measure- ment}

The apparatus used for the carbon monoxide adsorption work was a conventional glass system. A sample of the used catalyst was put in the vacuum apparatus. After hydrogen was passed through the bed of the sample for $2 \mathrm{hr}$ at $250^{\circ} \mathrm{C}$, the sample was evacuated for $1 \mathrm{hr}$ at same temperature. After cooling to room temperature, a carbon monoxide isotherm was measured. The adsorption was found to approach saturation under the pressure near $40 \mathrm{cmHg}$.

Amount of carbon monoxide adsorbed on $\mathrm{ZnO}-\mathrm{Cr}_{2} \mathrm{O}_{3}$ catalyst was very small. The net adsorption amounts due to copper metal might be calculated by subtracting the amount adsorbed on $\mathrm{ZnO}-\mathrm{Cr}_{2} \mathrm{O}_{3}$ part from the observed amount of each catalyst. The resulting values

Table 1 Catalytic Activities under the Conditions of Steady-State, Atmospheric Pressure and LHSV=2 $\mathrm{hr}^{-1}$

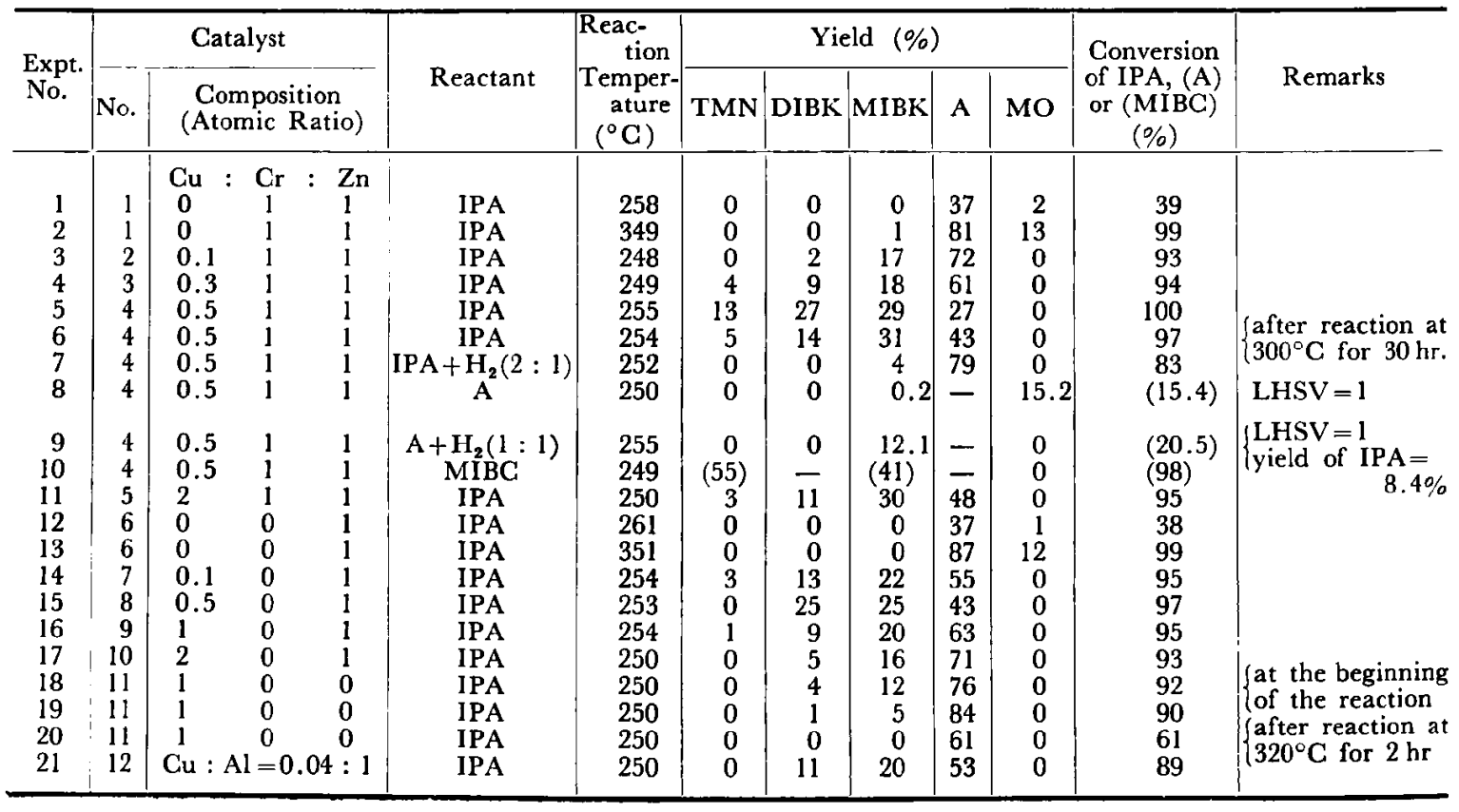


were multiplied with the cross section of carbon monoxide molecule, and then, the surface area of copper on the catalysts was obtained ${ }^{9}$.

\section{Results}

\subsection{Catalytic Activities}

The products of the condensation reaction of 2-propanol (IPA) were mainly 4-methyl-2-pentanone (MIBK), 2,6-dimethyl-4-heptanone (DIBK) and 2,6,8-trimethyl-4-nonanone (TMN). In addition to these compounds, acetone (A), dehydrogenation product of IPA, and small amounts of sec-alcohols corresponding to above higher ketones were obtained.

The changes of reaction results with time in a typical condensation reaction of IPA on catalyst-4 were shown in Fig. 1. Conversion of IPA was about $100 \%$ through the run. On

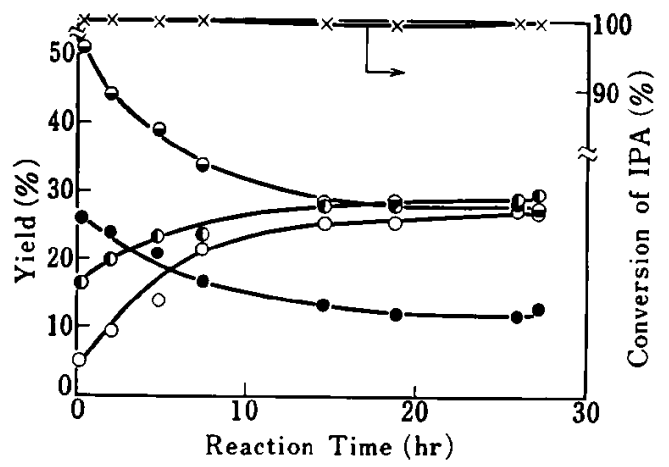

$x$; Conversion of IPA, $O, C, \ominus$ and $\ominus$; Yield of Acetone, MIBK, DIBK and TMN, respectively

Fig. 1 Activity-Reaction Time Relations with Catalyst-4 under the Conditions of Atmospheric Pressure, $\mathrm{LHSV}=2 \mathrm{hr}^{-1}$ and the Temperature of $250^{\circ} \mathrm{C}$

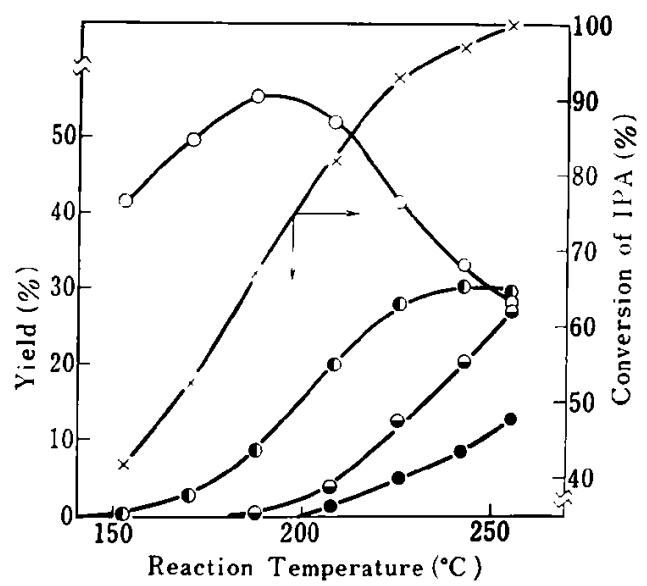

$x$; Conversion of IPA, $\bigcirc, 0, \ominus$ and $\odot$; Yield of Acetone, MIBK, DIBK and TMN, respectively

Fig. 2 Catalytic Activities of Catalyst-4 at the Steady-State the other hand, yields of acetone and MIBK increased gradually with reaction time, but that of DIBK and TMN decreased. After about $20 \mathrm{hr}$ 's reaction, yield of each product became constant (the steady-state).

Fig. 2 shows the relationships between yields of the products and reaction temperature at the steady-state using catalyst-4. Conversion of IPA increased with the rise of reaction temperature. Yield of acetone reached to the maximum value at $190^{\circ} \mathrm{C}$, but yields of higher ketones such as MIBK, DIBK and TMN increased monotonously.

Table 1 shows the yields of the reaction products obtained with two and three-component catalysts at the steady-state. On the catalyst-1, composed of two oxides of zinc and chromium, conversion of IPA was as low as $39 \%$, and acetone and small amount of mesityl oxide (MO) were obtained. By rising reaction temperature up to $350^{\circ} \mathrm{C}$ with this catalyst, most of IPA converted and yields of acetone and mesityl oxide increased to $81 \%$ and $13 \%$, respectively. But, MIBK, DIBK and TMN were not found in the product mixture obtained with catalyst-1 even at higher temperature. Activities of this catalyst did not change during the reaction at $350^{\circ} \mathrm{C}$.

By the progressive addition of copper to catalyst-1, conversion of IPA increased from $39 \%$ to $93 \sim 100 \%$, and yields of higher ketones became higher with increasing copper content in the catalysts to the maximum value (Expt.-5), and then decreased.

In experiments $7 \sim 10$, other compounds, which were considered to be formed during the reaction of IPA, were flowed with or without IPA on the catalyst-4, and interesting results were obtained. Hydrogen seems to reduce the condensation activity as shown in Table 1. When IPA was passed with hydrogen over the catalyst-4, only $4 \%$ of MIBK was obtained (Expt.-7). And in the case of mixing hydrogen to acetone feed, the decrease of condensation was also recognized (Expt.-8 and -9).

In the case of two-component catalysts (Catalyst $-7 \sim-10$ ), yields of ketones became constant after about ten hours. Products were just same as that obtained using three-component catalysts. On the catalyst- 6 , composed of zinc oxide, conversion of IPA and yields of acetone and MO were almost same as those obtained with the catalyst- 1 as described above, and did not change 
during the reaction at $350^{\circ} \mathrm{C}$.

When copper was added progressively to this catalyst, conversion of IPA increased suddenly from $38 \%$ to $93 \sim 99 \%$, and yields of higher ketones increased to the maximum value with catalyst-8, and then decreased with increasing copper content.

With copper catalyst, conversion of IPA was $92 \%$, and yields of acetone, MIBK and DIBK were $76 \%, 12 \%$ and $4 \%$, respectively at the beginning of the reaction (Expt.-18). On the other hand, at the steady-state, yields of these ketones were $84 \%, 5 \%$ and $1 \%$, respectively (Expt.-19). And after the reaction at $320^{\circ} \mathrm{C}$ for $2 \mathrm{hr}$ with the same catalyst, no higher ketones was obtained in the product mixture (Expt.-20).

With the catalyst-12, composed of copper and alumina $(\mathrm{Cu} / \mathrm{Al}=0.04 / 1)$, yields of acetone, MIBK and DIBK and conversion of IPA after ten hours' reaction, were $53 \%, 20 \%, 11 \%$ and $89 \%$, respectively (Expt. -21 ).

\subsection{X-Ray Diffraction}

Size of copper grain in the three-component catalysts after use were listed in Table 2. Several peaks due to metallic copper and zinc chromite were found in the $\mathrm{X}$-ray diffraction diagram of three-component catalysts and any peak due to zinc oxide, copper oxide or copper chromite was not found. Size of copper grain calculated by Scherrer's equation was very small in the catalysts containing a little copper, but it increased gradually with increasing copper content, and it was less than $200 \AA$ in all catalysts studied.

On the other hand, in two-component catalysts, only metallic copper and zinc oxide were found.

Table 3 shows values of copper grain size of

Table 2 Size of Copper Grain and Surface Area of Copper in the Catalysts

\begin{tabular}{|c|c|c|c|}
\hline $\begin{array}{c}\text { Catalyst } \\
\text { No. }\end{array}$ & $\begin{array}{c}\text { Composition of } \\
\text { Catalyst } \\
\text { (Atomic Ratio) }\end{array}$ & $\mid \begin{array}{c}\text { Size of Copper } \\
\text { Grain } \\
(\AA)\end{array}$ & $\begin{array}{c}\text { Surface Area } \\
\text { of Copper } \\
\left(\mathrm{m}^{2} / \mathrm{g}\right)\end{array}$ \\
\hline $\begin{array}{l}1 \\
2 \\
3 \\
4 \\
5 \\
6\end{array}$ & $\begin{array}{lcc}\text { Cu } & \text { Cr } & \text { Zn } \\
0 & 1 & 1 \\
0.1 & 1 & 1 \\
0.3 & 1 & 1 \\
0.5 & 1 & 1 \\
2 & 1 & 1 \\
1 & 0 & 0\end{array}$ & $\begin{array}{r}- \\
\sim \\
40 \\
90 \\
130 \\
200\end{array}$ & $\begin{array}{l}0 \\
0.7 \\
1.0 \\
3.8 \\
2.3 \\
0.3\end{array}$ \\
\hline
\end{tabular}

Table 3 Size of Gopper Grain in the Catalyst-4 before and after Reaction

Before Reaction

After Reaction at $250^{\circ} \mathrm{C}$ for $20 \mathrm{hr}$ (Expt.-5)

After Reaction at $300^{\circ} \mathrm{C}$ for $30 \mathrm{hr}$ (Expt.-6)

$70 \AA$

$90 \AA$

$110 \AA$ the catalyst- 4 before and after reaction. Size of copper grain increased from $70 \AA$ to $90 \AA$ or $110 \AA$ by the reaction.

\subsection{Surface Area of Copper}

Values of surface area of copper in three-component catalysts with different copper content, determined by carbon monoxide adsorption measurement, were also listed in Table 2 .

\section{Discussion}

With the catalyst-1 (zinc oxide-chromium oxide) and catalyst-6 (zinc oxide alone), yields of higher ketones were constant with reaction time and they were very low even at $350^{\circ} \mathrm{C}$. On the other hand, with three-component catalysts containing copper, yields of condensation products decreased gradually with reaction time but were higher than that with the catalysts without copper even at the steady-state. Same results were obtained by using catalyst-11, composed of copper alone. From the results mentioned above, it is considered that condensation activities of these catalysts and their decrease with reaction time are due to the existence and the state-change of copper in the catalysts, respectively.

Murakami et al. insisted that in the case of the reaction of IPA with copper-chromium oxidezinc oxide, condensation of acetone occurred at zinc chromite part and that hydrogenation of the resulting mesityl oxide occurred at copper part of the catalyst ${ }^{5)}$, however, copper(catalyst-11) itself has higher condensation activity than zinc chromite (catalyst-1), especially at the beginning of the reaction (Expt.-18).

With catalyst-12, composed of copper and alumina hydrate, yields of MIBK and DIBK and conversion of IPA at steady-state were $20 \%$, $11 \%$ and $89 \%$, respectively (Expt.-21). In this case, since this alumina hydrate*1) is thought to have neither condensation activity nor hydrogenation activity, it is very reasonable to consider that copper is responsible to condensation.

In this paper, the conception of converted yield, $X$, is defined as follows and used in order to express condensation activity.

$$
\begin{gathered}
X=1 / 2 \times\left(Y_{\text {MIBK }}+Y_{\text {MO }}\right)+2 / 3 \times\left(Y_{\text {DIBK }}\right) \\
\left.+3 / 4 \times\left(Y_{\text {TMN }}\right) * 2\right)
\end{gathered}
$$

*1) According to X-ray diffraction test, catalyst-12, which was heated and reduced at $250^{\circ} \mathrm{C}$ for $5 \mathrm{hr}$, was composed of metallic copper and böhmite.

*2) In above equation, there is no term due to 5membered products of condensation, namely $\neg$ 


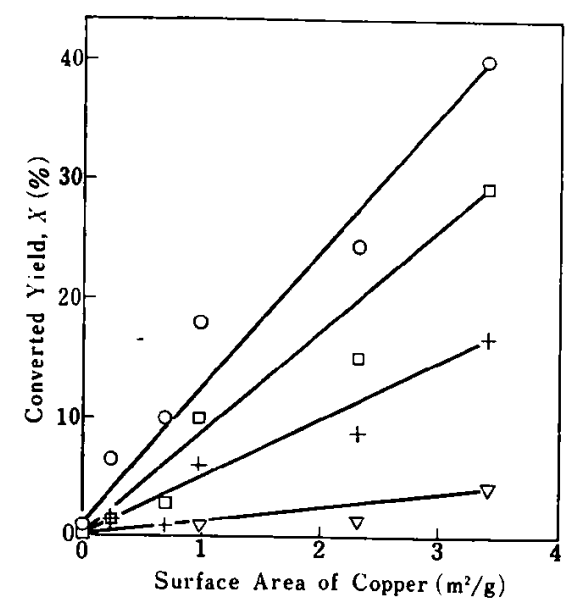

$O ; 250^{\circ} \mathrm{C}, \square ; 230^{\circ} \mathrm{C},+; 215^{\circ} \mathrm{C}$ and $\nabla ; 180^{\circ} \mathrm{C}$, respectively

Fig. 3 Relationships between Converted Yield and Surface Area of Copper

Here, $Y_{P}$ stands for yield of each suffixed product, $P$, based on IPA fed. Numerator and denominator of each coefficient stand for the number of condensation reaction to get each ketone from IPA and/or acetone and stoichiometric number of IPA to form each ketone, respectively. Therefore, converted yield is thought to be proportional to frequency of condensation reaction.

Fig. 3 shows the relationships between the values of converted yield at various temperatures and surface area of copper in the three-component catalysts. Apparently, these two kinds of value are proportional to each other at every temperature. It is suggested that condensation activity is due to the existence of copper and depends on the amount of surface area of copper instead of copper content.

Three different reaction paths have been proposed for the synthesis of MIBK from IPA and/ or acetone. First one is carried out via direct condensation between IPA and acetone ${ }^{2), 4)}$. Second one is carried out via regular ketonic condensation of two molecules of acetone, a subsequent dehydration of the resulting diacetone

$\checkmark$ ketones containing fifteen carbon atoms in them, because it is considered that higher ketones than TMN have little probability to being formed. DIBK or TMN has no active methyl group next to carbonyl group and may not react each other. So, it is not necessary to consider any other term due to higher ketones than TMN for converted yield. The concept of converted yield is available for all three reaction paths described below. alcohol and a hydrogenation of the resulting mesityl oxide by gaseous hydrogen ${ }^{5}$. Third one is nearly same as the second one and differs in only hydrogenation process, that is, MIBK is produced by a hydrogen transfer from IPA to resulting diacetone alcohol and a subsequent dehydration'1).

It was not examined in this study which reaction path can be applied for the condensation reaction. However, same paths may be applied for explaining DIBK or TMN formation by various combinations of acetone, MIBK and corresponding sec-alcohols, because acetone and MIBK as raw materials to DIBK or TMN have active methyl group next to carbonyl group in each structure.

As previously mentioned, with the catalyst-4, yields of higher ketones decreased with reaction time (Fig. 1), especially rapidly at higher temperature (Expt.-6). And this decrease seems to correspond to the increase of size of copper grain as shown in Table 3. Since there may be some size distribution of copper grain, the values listed in Table 3 are considered to be average values of various sizes of copper grain existing in the catalyst. So, the increase in these values found means the decrease in the number of smaller copper grain and the increase in that of larger ones probably.

It is suggested that condensation is mainly owing to the smaller grains and hydrogenation to the larger ones.

\section{Acknowledgement}

The authors are very grateful to Dr. H. Uchida for many suggestions for this work.

\section{References}

1) Ipatieff, V. N., Haensel, V., J. Org. Chem., 7, 189 (1942).

2) Kudo, S., Kogyo Kagaku Zasshi, 58, 785 (1955).

3) Fujii, R. et al., Japanese Pat., 34-517 (1959).

4) Kawamoto, K., Bull. Chem. Soc. Japan, 34, 161 (1961).

5) Murakami, Y., Onda, Y., Kogyo kagaku Zasshi, 72, 1033 (1969).

6) Ogino, Y., Oba, M., Uchida, H., Bull. Chem. Soc. Japan, 33, 358 (1960).

7) Uchida, H., Isogai, N., Oba, M., Hasegawa, T., ibid., 40, 1981 (1967).

8) Akamatsu, H., Takahashi, H., "Jikken Kagaku Koza", Vol. 4, 238 (1956) Maruzen, Tokyo.

9) Sinfelt, J. H., Taylor, W. F., Yates, D. J. C., J. Phys. Chem., 69, 95 (1965). 